\title{
*A Study of Macules in Nerve Leprosy
}

With particular reference to the "Tuberculoid" Macule. JoHN Lowe.

The Term "Macule."

The term macule (Latin macula, a spot) has been in use in dermatology for many years. The term is defined in a medical dictionary as " a small discoloured patch or spot on the skin not elevated above the general surface." Similar definitions are given in most text books of dermatology.

Among workers on leprosy, however, the term has been used with a wider meaning, and the Leonard Wood Memorial Conference on Leprosy suggested using it for " circumscribed areas of skin showing changes in colour, sometimes with slight elevation or depression." In this study we propose to use the term in a still wider sense to indicate any circumscribed area of the skin which shows colour changes, even if there is marked elevation above the general skin surface.

The Term ' Tuberculoid."

This term has been applied by various workers on leprosy to indicate leprous lesions (usually macules or affected nerves) which show pathological and histological appearances which are more like the changes seen in the " tubercles " of tuberculosis than those seen in the ordinary lepromatous tissue.

In ordinary lepromatous tissue the granulomatous change is usually of a rather diffuse nature, and the characteristic cell is the "foamy lepra cell" in which large numbers of bacilli are present. Multinucleated foamy cells may be present, but not giant cells of the Langhan's type.

*Reprinted from Leprosy in India, Vol. 8, No. 3, July, 1936. The original article shows 35 illustrations, of which we reproduce only 9. 
In the tuberculoid lesions of leprosy, however, the granulomatous change is typically much more focal, and the characteristic cell is the epithelioid cell with little or no foamy change. Bacilli are usually very few, and multinucleated giant cells of Langhan's type, sometimes very large with dozens or hundreds of nuclei, are often found lying inside the foci of granuloma. There is often a tendency to cell necrosis. The resemblance to a " tubercle" is very close.

The use of the term "tuberculoid " to indicate this type of leprous lesion has been criticised by some workers, and certainly the term is open to objection; but it is understood by most workers on leprosy, and no other suitable term has yet been suggested to replace it. We therefore continue to use it.

\section{Tuberculoid Changes in Leprous Lesions.}

The presence of tuberculoid changes and necrosis in leprous lesions of the skin and nerves in "maculo-anæsthetic" leprosy was reported in 1884 by Arning. Since then dozens of publications have appeared on the subject. The matter was demonstrated and discussed at the International Leprosy Conferences held in Berlin 1897, Bergen 1909 and Strasbourg 1923. The older literature of the subject is very well reviewed by Jadassohn, Klingmuller and Jeanselme in their volumes on leprosy. Recent valuable studies of the subject have been made by Henderson, Muir, Chatterji, Wade and various Japanese workers. The condition has for many years been well recognized by some workers and its chief clinical and pathological features have been established, although it is noteworthy that such an experienced and distinguished worker as Lie in Norway has in the past cast doubt upon the soundness of these findings and apparently thought that the condition was due to infection with $M$. tuberculosis. He states, however, that the condition is extremely rare in lepers in Norway, where indeed leprosy has now nearly died out; nevertheless the descriptions and illustrations of " maculo-anæsthetic" leprosy given many years ago by Danielssen in Norway are so very similar to the descriptions of "tuberculoid " leprosy given by other workers, that one wonders whether the apparent difference of opinion is not based chiefly on a difference of terminology.

Tuberculoid changes in leprous lesions are reported most frequently by workers who have studied biopsy material, and in our experience it is a comparatively rare post mortem finding. There are, we believe, two reasons for this. Firstly, tuberculoid changes are seen in the less severe forms of 


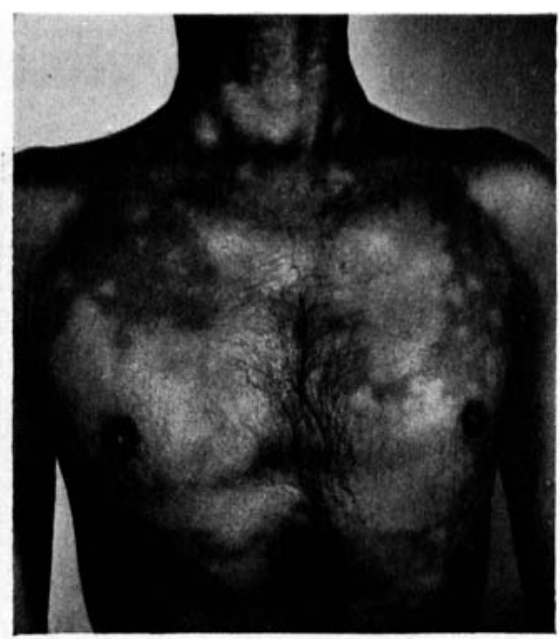

IFIG. 1 .

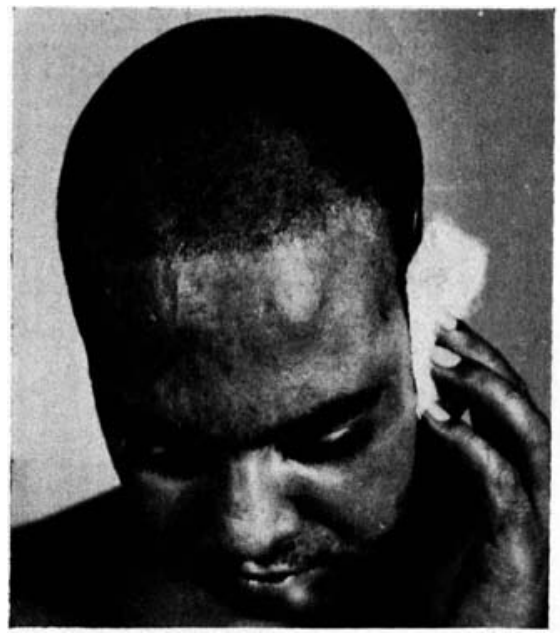

FIG. 3.

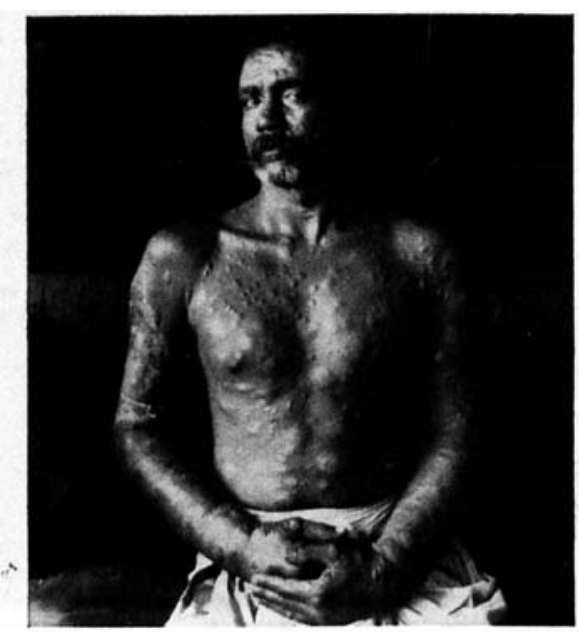

Fig. 5.

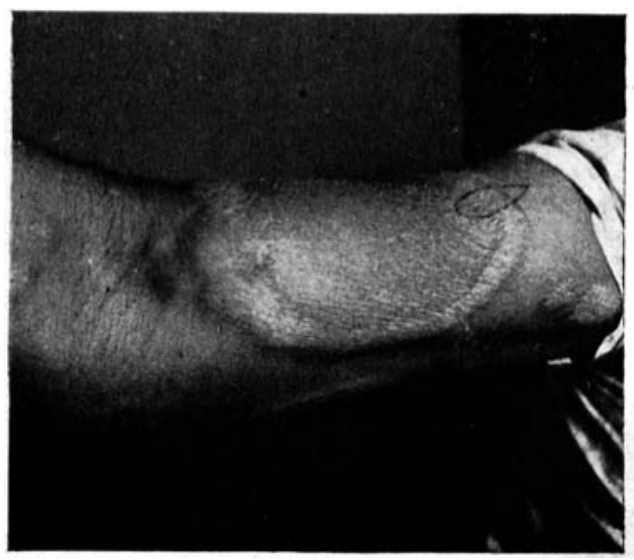

FIG. 2

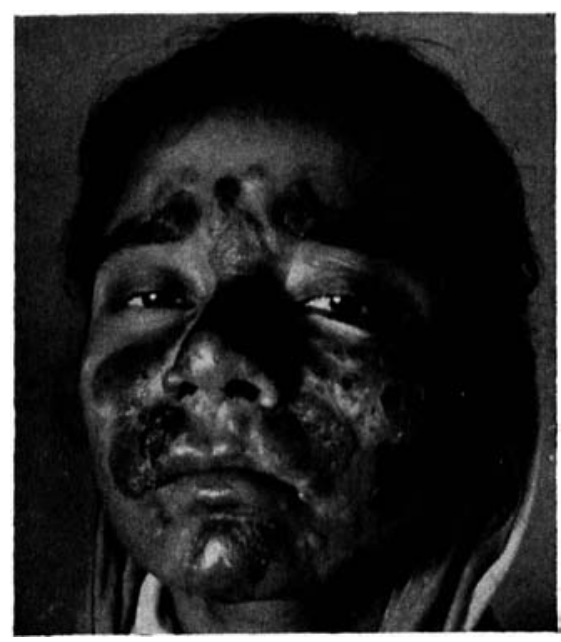

FIG. 4.

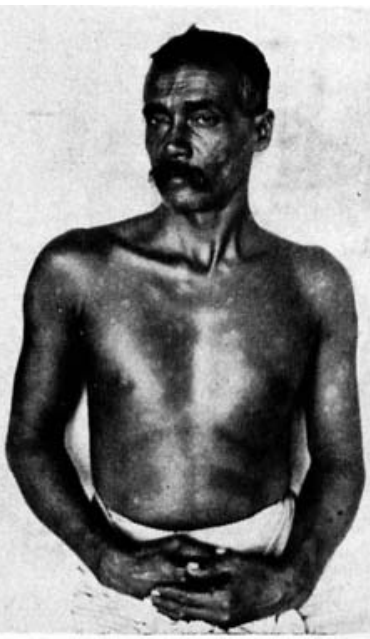

Fig. 6. 


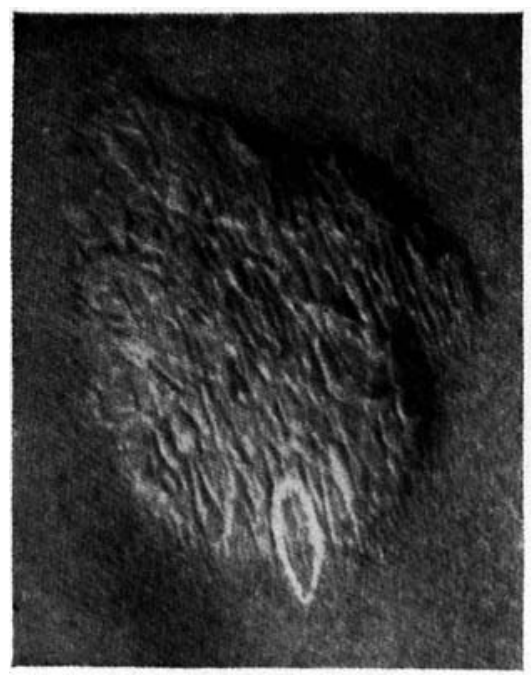

FIG. 7.

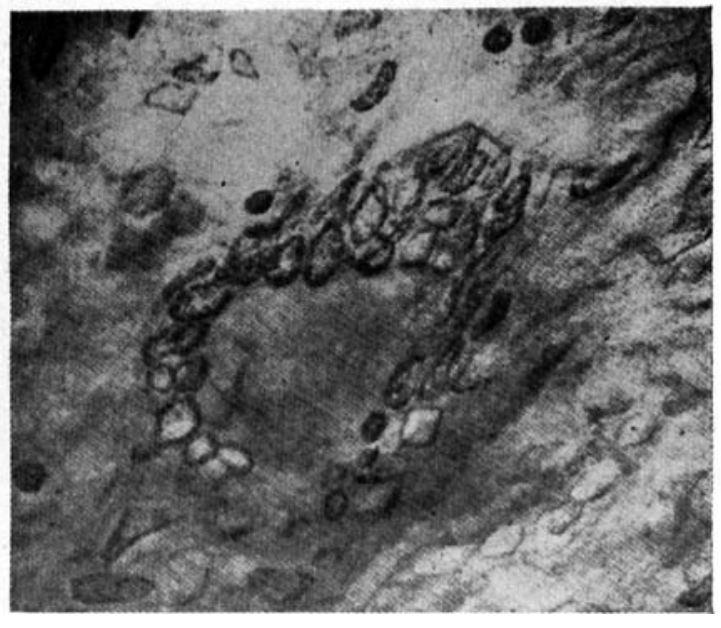

Fig. 8

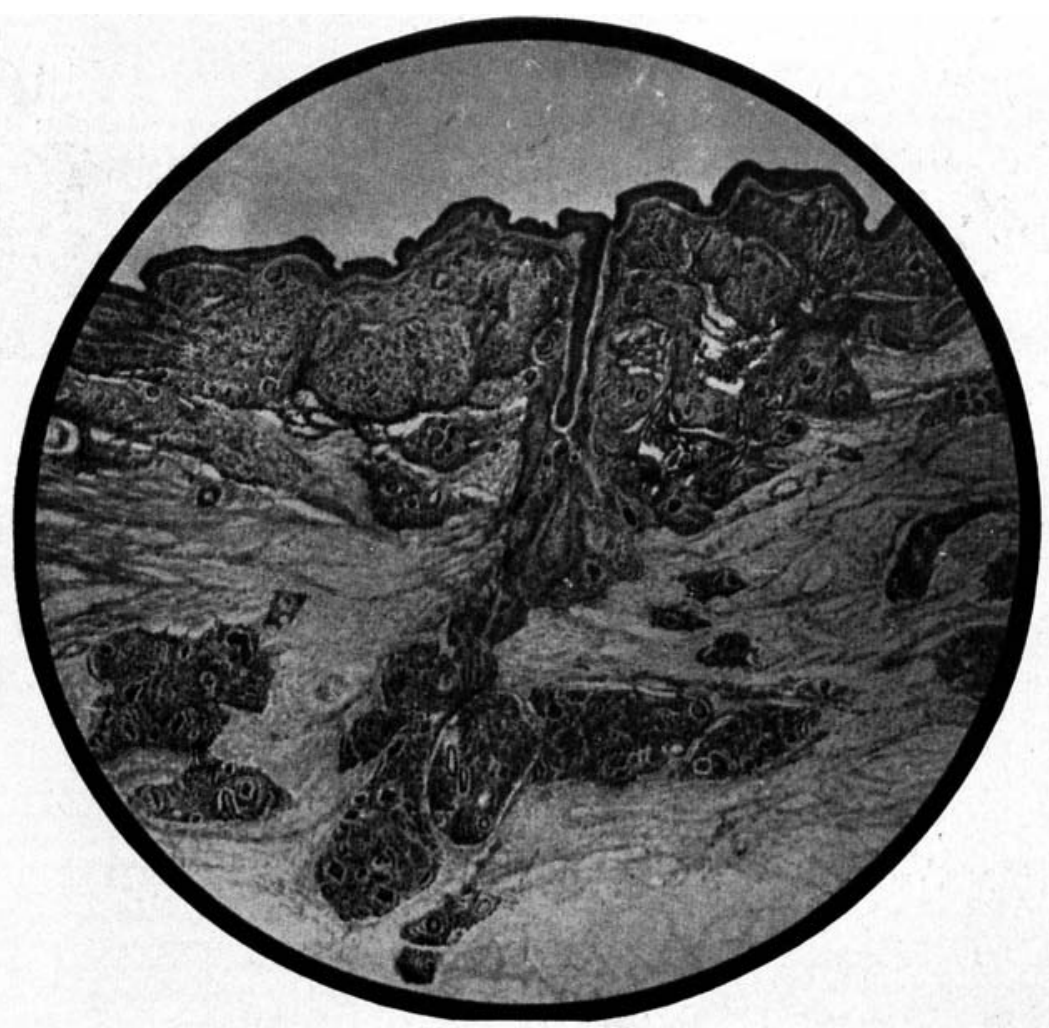

FIG. 9. 
leprosy which do not cause death; and secondly, intercurrent diseases which may cause death in such cases of leprosy, also cause the previous disappearance of tuberculoid changes. Tuberculoid changes are, we believe, often only a temporary phase in leprous lesions.

For these reasons we believe that the study of tuberculoid changes must be made in biopsy material, and that the significance of the changes can only be determined by the observation of cases over long periods. Another important point in studying the pathology of the condition is that it is sometimes necessary to study several sections from one block of tissue, since a single section may not reveal certain of the characteristic findings of these lesions.

The Incidence of Tuberculoid Macules.

The present author, after working on leprosy for some years in South India and after seeing a little of leprosy in other parts of the East, came to work in Calcutta, and on seeing the work of the Leprosy Out-patient Department of the School of Tropical Medicine was at once struck with the great number of patients who showed macules. Most of these macules were what have been described in leprosy literature as tuberculoid macules. He formed the opinion that these cases of macular leprosy, though seen elsewhere in small numbers, are much more numerous in Bengal and particularly in Calcutta than they are in South India and many other countries, although they are reported as being common in Japan and less common in South Africa and South America.

The Macules of "Cutaneous" Leprosy.

Before going on to discuss the macules of nerve leprosy we will mention briefly the macules often seen in cases of " cutaneous" leprosy. These are merely local manifestations of a diffuse leprotic invasion of the skin, which is usually easily detected. The macule of cutaneous leprosy is usually seen on the trunk (see fig. 1). Its margins are rather ill defined, but there is a definite loss of pigment in circumscribed areas of skin, while the skin between the macules often shows leprotic changes. There is usually some erythema and thickening, but sensory changes are almost completely absent. Bacteriological examination shows many acid-fast bacilli and tuberculoid changes are not found. This type of macule is usually clearly distinguishable, clinically, bacteriologically and histologically from the macule of nerve leprosy and we will not discuss this type of macule any further. 
The Macules of Nerve Leprosy.

Our description is based on a careful study of these lesions as seen in patients in Calcutta. Since there is considerable evidence to show that the clinical manifestations of leprosy differ in different regions, it is possible that our findings may not entirely agree with findings of similar studies made elsewhere.

These macules show themselves clinically in three main forms, but as we shall explain later we do not believe these to be three different clinical and pathological entities, but merely three different manifestations of the same pathological process, one form of macule often developing into the other form.

The three main forms we shall call: (a) the flat pale macule, $(b)$ the annular macule with a flat centre and thick red margin and (c) the thick red macule or plaque showing thickening and erythema all over. The last two forms are those which have been described in the literature as " tuberculoid" macules. Muir has frequently referred to these lesions as "reacting" lesions. We class all these three as macules of nerve leprosy. Our reasons for doing so are given later.

Before describing the peculiar features of each of these three types of macules, we will briefly describe the features common to all three types.

Features common to all three types of Macules.

(a) Appearance.-The following are the chief characteristic appearances of these macules. They vary in size from about quarter of an inch in diameter to a foot or more in diameter. They may be round or oval but they are often irregular in shape. The margins are as a rule clearly defined but there are often tiny macules near the edge of large ones and the coalescence of several macules may occur. There is usually a very definite pigmentary change which nearly always takes the form of a partial loss of pigment, but a macule may be hypopigmented near the margin and hyperpigmented in the centre.

In addition the skin of the macule almost always shows a greater or less degree of depilation, the hairs either being few in number and feeble in the growth, or else being completely absent. Also impairment of the secretion of the sweat and sebaceous glands is often seen, and the skin becomes dry and scaly and desquamates (see figs. 4, 7). Sometimes the skin becomes so scaly that the lesions resemble those of psoriasis. Sometimes there is a " pebbled " appear- 
ance (see fig. 7) or elevation of the hair follicles so that the lesion looks like a patch of "lichen spinulosum ". These are the characteristic appearances, but frequently in India the clinical appearances of macules are masked by scarring due to local application of caustics or to scarification, two popular forms of indigenous treatment.

(b) Sensory changes.-There is practically always some change of cutaneous sensibility on the macules, the first such change often being a feeling of numbness accompanied by a sensation of tingling which patients often describe as " pins and needles" or as being " like ants' bites ". On testing, various abnormalities of sensation may be found in various parts of the macules. The changes are usually most marked in the centre and less marked at the margin. The earliest change is often the impairment of heat and cold sensation, and often the sensation of pain is impaired (analgesia). Later the sensation of light touch is lost. There may be anæsthesia to light touch in the centre, and analgesia at the margin.

(c) Nerve thickening in connection with the macule.One of the common findings in Calcutta is that of thickened branches of cutaneous nerves supplying the macules. These branches, normally fine twigs difficult or impossible to palpate, may be so much thickened as to be very easily palpable and often visible. There are frequently nerve abscesses in these cutaneous nerves.

(d) The distribution of macules. - It is commonly said that certain areas of the skin of the body (for example the scalp, the palms of hands, the soles of the feet and the flexures) are rarely affected in leprosy, and it is true that in " cutaneous " leprosy these areas show little clinical evidence of involvement although pathological and bacteriological examination may often reveal lesions. In the type of nerve leprosy which we are describing, these areas are far from being immune, and the macules may be found anywhere in the body; on the palm, the sole, the scalp, the genitals, the axilla and the neck. Macules are, however, very commonly found on the face, on the arms, the legs and on the trunk.

(e) Healing of macules.-Macules often cease to spread and become inactive either for long periods or permanently. While this healing of macules is common, the infection of ten spreads up the nerve branches to nerve trunks and in these sites the infection may continue active for a long time. The skin appears to have more immunity than the nerves. The healing of macules is illustrated in fig. 6 . 
Individual Features of the three main varieties of Macules.

(a) The flat macule (see fig. 3).-This type of macule may originate in either of two ways. It may start as a flat pale macule of small size and spread radially in its original form, or it may be found as the result of the subsidence of erythema and thickening in the "annular" and "thick" macules.

In macules of this type the sensory changes are often marked and the thickening of the branches of cutaneous nerves is often slight. Compared with the other types of macule, this type is very chronic and rather inactive. There is very little thickening of the skin or of the cutaneous nerves supplying it, because of the absence of the sub-acute inflammatory processes, which are seen in the other two types of macule, and this type of macule is often merely the scar left as the result of the subsidence of the inflammation in the other types of macule. Bacteriological examination by ordinary methods practically always gives negative results, and even by examining serial sections it is often impossible to detect bacilli. Bacilli if found are few in number. Sometimes, however, the macule does show a gradual radial spread, but in these cases there will nearly always be found slight erythema and thickening at the margin which means that it really belongs to the " annular " type.

The flat pale macule may show no change for many years. In some cases after a short or longer period of quiescence, signs of inflammation, erythema and thickening may appear and the lesion may assume the characteristics of the annular or thick macules. In many cases no such signs of activity are ever seen, and the macule may gradually fade though some sensory change is often permanent.

(b) The annular macule (see fig. 2).-Here a different state of things is found. This is definitely an active lesion, and there are signs of inflammation in the margin of the macule and in the nerves supplying it.

This type of macule arises in one of two ways. It may result from the occurrence of inflammatory changes in the margin of a macule which was previously of the flat type; or it may develop from the thick macule by the occurrence of subsidence of the inflammation at the centre while spread continues at the margin. The appearances of the macule are typically as follows. Round the margin is a narrow outer zone of depigmentation with little or no erythema and thickening; just inside the margin is the intermediate zone of thickening and erythema which varies considerably in width from about one quarter of inch to an inch or more; 
this thickening may be very slight or very marked. In the centre is the zone where the thickening and erythema have subsided and it thus often appears depressed.

The sensory changes are usually most marked in the central zone, less marked in the intermediate zone, and least marked in the outer zone.

The results of ordinary bacteriological examination in this type of macule vary very much. Sometimes no bacilli, sometimes a very few and occasionally a moderate number of bacilli will be found near the margin of the macule. The number of bacilli never approaches the number seen in the lesions of nodular leprosy. Examination of serial sections of these lesions shows bacilli in many cases, usually very few bacilli, and often situated fairly deeply in the corium.

As we have said this condition is an active one. The macule or macules (for they are frequently multiple) may appear fairly suddenly and grow fairly rapidly, spreading at the margin and healing at the centre. The spread sometimes continues for only a few weeks or months, and then the signs of inflammation gradually subside and the macule assumes the appearance of the flat pale macule of the inactive type. During this healing process, the superficial layers of the epithelium become dry and wrinkled and are finally shed often in the form of scales. Sometimes however signs of activity will be present for years, or may disappear and later reappear and the macule may show several periods of activity and of quiescence which may extend over many years. We have seen patients with one or more large active macules, who have given a history indicating alternating periods of activity and quiescence of the macules over periods as long as fifty years. More frequently the macule after a time becomes quiescent and later the process becomes finally arrested. In some cases, however, the lesions take on the "cutaneous" form and there develops a diffuse infiltration of the skin and the macules fade. The latter development is not common.

(c) The thick macule (see figs. 4, 5, 7).-This is, we believe, simply a more marked form of the same active process as is seen in the " annular" type of macule. The signs of inflammation are more marked and more extensive, the whole patch being red and thick, sometimes very thick the macule standing out a quarter of an inch above the general skin surface; and on palpation much subcutaneous thickening can also be felt and the thick mass has the consistency of cartilage. The macule feels hot, for the skin temperature 
is raised above that of the surrounding skin. The patient may complain of a severe burning sensation. Occasionally the inflammation may go on to actual ulceration usually seen at the margin of the lesions (see fig. 4). Ordinary bacteriological examination in these cases sometimes shows no bacilli, but usually a few bacilli are found, and sometimes bacilli are quite numerous, though never as numerous as in "skin " leprosy. There is nearly always marked inflammation of the cutaneous nerves supplying the macule.

There may be only one such macule in the body, or there may be many, occasionally hundreds of such macules (see fig. 5). They often appear suddenly and spread rapidly for a time, and they may be so numerous and widespread that unless one is familiar with the condition the case may appear like one of a severe form of nodular leprosy (see figs. 4, 5). Clinical experience and careful examination will make it possible to distinguish this condition. The lesions, though they may be very marked and very numerous, are circumscribed, the skin between the lesions being perfectly normal, whereas in nodular leprosy the lesions are much more diffuse and the skin between the marked lesions shows slight leprous infiltration. In this condition lesions commonly appear in sites where leprous nodules are rarely seen (e.g. palm, soles, flexures, arm-pits, groins, genitals, etc.). There is nearly always marked nerve thickening which is rarely seen in nodular leprosy; in these lesions bacilli are few, while in nodular leprosy they are always very numerous. This condition rapidly subsides while nodular leprosy does not. These are the distinguishing points.

The thick red macule is usually only a temporary phase in the development of the lesion. After appearance the lesions spread for a time limited as a rule to a few weeks or months and then begin to subside. The subsidence usually begins at the centre of the macule, and at this stage the lesion has an annular form as described above. Usually within a few months, the signs of inflammation disappear from all the macules, and there are left the flat pale macules described above. This clinical improvement is accompanied by a marked diminution in the number in and finally a disappearance of the bacilli from the lesions. After acute inflammation, healing is often accompanied by marked scarring.

The condition of inflammation may recur but not very commonly; the acuter the inflammatory condition to begin with, the less appears to be the tendency to recurrence when it has subsided. 
In a few cases, however, the appearance of these markedly inflamed macules is followed by the nodular form of leprosy with diffuse leprous lesions in the skin, but when this occurs, the macules fade though some anæsthesia usually remains.

Pathology.

We will describe only briefly the pathological changes seen in biopsy material taken from these macular lesions.

(a) Flat pale macule.-There is no change visible to the naked eye except the loss of pigment, and thickening of the fine nerves entering the patch of skin.

On section, however, various slight changes are found. The epidermis is unaffected except for the diminution of pigment in the basal layer. Immediately under the epidermis usually around the skin capillaries are seen here and there small collections of cells. Similar collections of cells are found round the hair follicles, sebaceous glands and sweat glands. Deeper in the corium are seen a few similar cellular foci. Deeper still the fine nerve branches may be seen cut in section and these show infiltration with similar cells.

The cells are chiefly of "epithelioid" nature. Occasionally a giant cell of Langhan's type may be found. There may be a few lymphocytes and leucocytes. In old macules healing or healed, fibroblasts may be found. Very occasionally one or two bacilli may be found in the granulomatous foci after prolonged searching in many sections.

(b) The annular macule.- In the central area the changes are similar to those seen in the flat pale macule but are usually more marked unless the process of healing is very well advanced. In the erythematous intermediate zone, the changes are much more marked ( fig. 9). The thickness of the corium is greatly increased and the epidermis is somewhat thinned and stretched over the swollen corium. In the superficial layers of the corium, and round the hair follicles. sweat glands and sebaceous glands are seen masses of inflammatory cells. In lesions showing marked thickening these masses coalesce and there is often inflammatory œdema. The cell masses often extend deep into the corium, where also are seen cut in section the cutaneous nerve branches markedly thickened and granulomatous, and surrounded by inflammatory cells. By cutting serial sections it is often possible to trace the direct continuity of the granulomatous masses in the corium with the granulomatous masses in and around the nerves. It therefore seems probable that the round or oval foci of inflammatory cells often seen in sections are not really isolated foci, but are 
cross sections of granulomatous cords arising from the superficial layers of the corium and extending up and around the nerve branches.

The cells are similar in nature to those already described in the flat pale macule, but the characteristic feature is the occurence in or near the centre of the masses of multinucleated giant cells of Langhan's type (see fig. 8). These are found both in the corium and in and around the nerves.

Bacilli are frequently found in the granulomatous masses, nearly always few in number. They are usually found at the margin of cell masses and not in the centre near the giant cells. On a few occasions however we have found a few bacilli inside the giant cells. Bacilli are more numerous in the nerves than in the corium.

In the outer depigmented zone of the annular macule, the changes are similar but less marked and bacilli are frequently found, possibly more frequently than in the intermediate thick zone.

Thus in the three zones of this type of macule we get three different stages of the inflammatory process. In the outer zone there is apparently multiplication of bacilli with the early phase of tissue reaction. In the intermediate zone there is intense tissue reaction with giant cell formation, and the destruction of bacilli, and in the inner zone there is subsidence of the inflammation and healing. While this is occurring in the skin, the infection and inflammation is spreading up the nerves supplying the skin, and here the process of healing is slower and of ten less complete.

(c) The thick red macule.-In this form of macule the pathological changes are essentially the same as those seen in the thick portion of the annular macule, but the condition is more acute, the bacilli more numerous and the tissue reaction more marked. The same appearance of granulomatous masses with giant cell formation is seen, and the process may go on actually to caseation, and ulceration of the skin may occur.

When the inflammation subsides, as it nearly always does, healing takes place often with the formation of a considerable amount of fibrous tissue and scarring which may cause deformity and disfigurement in such places as the face.

Pathological changes seen in macules which become lepromatous.-In lesions in which this change occurs the following phenomena are seen. The number of bacilli increases and this change is accompanied by the development of "foamy " changes in the cells. The Langhan's giant cells disappear, and the focal arrangement of the granuloma 
is lost, because of the development of the more diffuse lepromatous change.

\section{The Nature and Causation of "Tuberculoid" Lesions.}

We may state at the outset that we believe that these lesions are caused by the presence of the acid-fast bacillus M. lepræ in the skin. We will however discuss other theories regarding their causation which have been advanced by different workers at different times.

It has been suggested that these lesions are not due to leprosy but to tuberculosis of the skin. Workers who have advanced this view are those who, as they themselves state, have seen very few such cases and who have had little opportunity of studying the condition closely. In opposition to this theory we would quote the following facts which are in our opinion conclusive. In Calcutta about $40 \%$ of all the cases of leprosy and about $70 \%$ of all our cases of nerve leprosy show, or have shown, such lesions. We see several hundreds of such cases every year in Calcutta where skin tuberculosis is uncommon. Practically all these cases show other definite evidence of leprosy, anæsthesia of skin, and thickening of nerves supplying the macules, which is often very marked and which cannot possibly be due to tuberculosis. All attempts to isolate tubercle bacillus from such lesions by inoculation of guinea-pigs have failed even when acid-fast bacilli have been found in the inoculum. Some of these patients later show typical nodular leprosy.

Other workers have acknowledged that the lesions are due to leprosy, but, because of the scantiness of acid-fast bacilli in the lesions, have postulated that the casual agent is a non-bacillary, non-acid-fast form of the organism, possibly a filter-passing form. The only evidence in favour of the existence of a filter-passing form of the leprosy organism is the work of Markianos on the rat-leprosy organism, and this we have completely failed to verify. A few years ago Rodriguez reported the finding of non-acidfast granules in leprous lesions, but this has not been verified by us, or as far as we know by anyone else, and no further reports of such a nature have appeared. All attempts made by us to detect a non-acid-fast form of the organism have failed. Unna at one time considered that macules of the type we are discussing were due not to bacilli but to toxins of the bacillus acting through the nerves. Later he abandoned this view.

Still another explanation of these lesions of the skin is that they are of a trophic nature due to the leprous lesions 
of the nerves supplying the skin. Before we studied the matter closely we were inclined to hold this view, but we now find that this view is untenable as is demonstrated by the following observations. The skin lesions appear first and the nerve lesions appear later. The nerve lesions appear in the distal portion of the nerve and spread upwards. The skin lesions often do not correspond to the skin distribution of any cutaneous nerve or nerve trunk. If the skin lesions appear on an area of skin which is supplied by several cutaneous nerves of different origin (i.e. arising from different nerve trunks), the inflammatory change often spreads up into all these cutaneous nerves and nerve trunks. These facts we think prove conclusively that the lesion originates in the skin, and since several or many such lesions often appear more or less simultaneously in various parts of the body, it appears probable that the causative organism gets into the blood stream and is deposited in various sites in the skin of body.

In what form is this organism? We believe that it is the ordinary acid-fast bacillus.

When we first started a close study of these lesions, in very few of them could we find any acid-fast bacilli. Smears made by the ordinary " slit " and "clip " methods nearly always gave negative results. By examination of biopsy material we could find a few bacilli in perhaps $10 \%$ of cases examined. When, however, we began to examine lesions more thoroughly, searching for bacilli in not one, but, if necessary, in six or eight sections, the percentage of positive findings rose, and when as the result of a careful study we improved our staining methods, the percentage of cases in which we found bacilli rose to about sixty. We believe that careful examination will reveal bacilli in nearly all macules showing definite clinical signs of activity. The depigmented patch of long standing with no clinical signs of activity is often merely the scar of a previously active lesion, and in such scars bacilli will not be found; but in patches showing any erythema, thickening and extension at the margin, patient search will as a rule reveal bacilli. In such cases bacilli can also be found often in considerable numbers in the cutaneous nerve twigs of the macule, and in a few cases we find them in the nerves and not in the skin. This is we believe due to the infection being overcome earlier in the skin than in the nerves.

Although, in active macules, bacilli can usually be found, it is quite true that the number is very small to produce the marked lesions often seen. In nodular leprosy one of the 
striking things observed is the enormous number of bacilli often found in lesions which are clinically very slight, yet in maculo-anæsthetic leprosy the reverse is found. How can this be explained?

It has been suggested that two different strains of the organism with markedly different virulence may cause these two markedly different forms of the disease. On this basis, however, it is impossible to explain why an infected person will sometimes show first the "maculo-anæsthetic" type and later the nodular type of the disease. For this reason most workers are agreed that the organism does not vary, but the soil in which it is planted varies markedly. The tissues of some persons have the power of reacting very strongly to very small numbers of the leprosy organism with a resulting limitation of the extent and severity of the infection, and in such persons the maculo-anæsthetic form of the disease is seen, while the tissues of other persons have not this power, and in such persons the disease tends to take the severer nodular form. In the cases which start with the maculo-anæsthetic form and later show the nodular form the reacting powers of the tissues are present at first and later are impaired or lost. This view is based partly on a study of the results of the "leprolin" test in patients in different stages of the disease. The nature of this reacting power of the tissues to the bacilli is not clear and cannot be discussed here, but it appears to be related to the phenomena of allergy and immunity.

We may summarize our views on the subject by saying that we believe that the different clinical appearances of the macules of maculo-anæstheticleprosy are merely different phases of the same pathological process which is caused by a relatively small number of the acid-fast bacillus $M$. lepræ in the lesions, and by the resulting marked tissue reaction.

Our views on this subject are, we realise, somewhat different from those commonly held. The ordinary depigmented anæsthetic patch which we have called the flat pale macule is usually regarded as being in a different category from the inflamed patches of " annular " or " plaque " type which, because of the peculiar focal arrangement of the granuloma and because of the giant cells, are often called tuberculoid macules. Our clinical and pathological studies of some hundreds of macules have not supported this idea. In nerve leprosy in Calcutta we find practically no macules in which there is no evidence of present or past inflammatory change of " tuberculoid" nature. 
The Relation of Inflammatory Changes in Macules and Nerves to "Lepra Reaction."

The term "lepra reaction" has not been very clearly defined. In common with most other workers we have in our writing used the term to indicate the acute or sub-acute " exacerbations" of the disease usually of a temporary nature, and have included under this term the "exacerbation" seen in cases of nodular leprosy with swelling of old lesions, appearance of new lesions, associated with fever, and also the "exacerbation" seen in cases of maculo-anaesthetic leprosy when the macules and nerves show the acute or subacute inflammatory changes we have described, but in which there is little constitutional disturbance or fever.

We doubt very much the advisability of using one term "lepra reaction" to include these two conditions which may be due to quite different causes, and which occur typically in patients in whom the clinical and immunological conditions appear to be very different. These "acute exacerbations " in cases of nodular leprosy though often temporary appear on the whole to be a bad sign, for they often recur and the patient often gets steadily worse. In maculoanæsthetic leprosy the "exacerbations" are usually less acute and take longer to subside, but subsidence is often not followed later by recurrence, and quite often it is followed by a prolonged inactivity and sometimes by permanent arrest of the disease. During the "exacerbation" however there is frequently permanent damage to nerves and resulting permanent deformity.

The difficulty of classing these two conditions under one name " lepra reaction" is being realized by workers in other countries particularly in Japan where much maculoanæsthetic leprosy is seen, and in Japan the term " erythema nodosum leprosum " has been used for "lepra reaction " of nodular type, and the reaction of macular type is regarded as being different. Hayashi has recently suggested that the term lepra reaction should be qualified by the addition of the words " neuro-macular type " or " nodular type" to make clear which condition is meant.

Wade has recently described "lepra reaction in tuberculoid leprosy" in cases showing macules similar to the "annular" macules we have described. $\mathrm{He}$ apparently regards the " reaction" as something superimposed upon the tuberculoid lesions, while we regard the mere presence of "tuberculoid" lesions as indicating at any rate a marked tendency to lepra reaction of the neuro-macular type. 
The Classification of Cases with Macular Lesions.

In leprosy journals there has been much controversy regarding the classification of cases showing macular lesions of "tuberculoid" type, in the scheme of classification suggested in the report of the Wood Memorial Conference, which is in common use; and it must be admitted that the report is a little ambiguous on this point.

We may quote the five relevant passages from the report :

(a) "Leprosy is a general disease; in no type are the lesions confined to a single tissue."

(b) "Clinically there are many cases that for practical purposes may be considered essentially "neural". They frequently have visible (usually hypopigmented) lesions of the skin, but in typical cases bacteriological findings by the usual methods are consistently negative."

(c) "The signs associated with nerve involvement tend to fall into two groups namely : (1) the macular which is characterized by disturbance of pigmentation, circulation and sensation in circumscribed areas, (2) acroteric."

(d) "Classification. Main types:-

Neural- "all cases showing evidence of actual or previous nerve involvement, i.e., alteration of sensation with or without changes of pigmentation and circulation, trophic disturbances, etc. These are not accompanied by leprotic changes in the skin."

Cutaneous-all cases showing leprotic lesions of the skin."

(e) "Definitions :-

Leprotic. It is suggested that the term "leprotic" be applied to those changes which present clinical or microscopic evidence of inflammatory process typically of granulomatus nature which are apparently caused by M.lepræ in them, in such lesions the organism can usually be demonstrated by the ordinary methods of examination."

The first three passages and the first sentence of the fourth passage justify the classification of cases showing even the "tuberculoid" type of macule as " neural" cases. The last two sentences of the fourth passage, and the fifth passage, are the sources of misunderstanding. On the one hand the tuberculoid lesion is definitely "leprotic" in the sense of the definition given; this would indicate the classification of such cases as "cutaneous". On the other hand in the tuberculoid lesion bacilli are usually not found by ordinary methods of bacteriological examination; this would support the idea of classification as " neural ", although the scheme of classification is primarily a clinical and not a bacteriological one.

The spirit of the report and not merely the letter of certain sections should be considered. The letter of some sections is not in keeping with the letter of other sections, but 
in our opinion the spirit of the whole section on classification leaves little room for doubt that tuberculoid lesions should be classified as " neural ". One's clinical and pathological knowledge supports this idea. The cases showing macular lesions, even multiple lesions of the "plaque" type, are usually clearly distinguishable from the "cutaneous" cases as described in the conference report. The clinical features, the pathological features, the bacteriological findings, and the prognosis are different. Surely then we should not hesitate to classify these cases as being of " neural "type, even if a few bacilli are occasionally found in smears taken from lesions. We are glad to note that in the recent literature of leprosy the classification of tuberculoid leprosy as a subtype of " neural " leprosy appears to be the rule.

We think, however, that the use of the term " neural " and "cutaneous" for the two main types of leprosy is partly responsible for the confusion which has existed. These terms were adopted by the Conference after long discussion and with some misgiving. We think that the old term " maculo-anæsthetic", and the term "neuro-macular", have much in their favour, for they do convey the idea that visible lesions of the skin may be seen in this type of leprosy; this idea is not conveyed by the term "neural ".

\section{Summary.}

1. The use of the terms " tuberculoid " and " macule" in connection with the lesions of leprosy, the occurrence of tuberculoid changes in leprous lesions, and the high incidence in Calcutta of lesions showing such changes are discussed.

2. The clinical, pathological, histological and bacteriological features of the various types of macule seen in cases of nerve leprosy are described and illustrated by photographs. The finding of acid-fast bacilli in practically all macules showing signs of activity is reported. The marked tendency of macules to spontaneous healing is described.

3. The opinion is expressed that the various types of macule seen in nerve leprosy are merely different manifestations of an inflammatory process of tuberculoid nature, seen in different stages of activity and quiescence. All active macules of nerve leprosy are considered to be of tuberculoid nature.

4. The causation of tuberculoid lesions is discussed and the opinion is expressed that they are associated with marked reacting powers of the tissues of the affected patients to the ordinary acid-fast organisms of leprosy, and not to a special 
strain of the organism to a toxin, to a filter-passing or other form of the organism, or to trophic nerve disturbance.

5. The occurrence of acute and sub-acute inflammatory changes in leprous lesions of the tuberculoid type is described. These have frequently been attributed to "lepra reaction". A contrast is made between these inflammatory changes which are usually followed by subsidence and often by arrest of the disease, and the inflammatory changes seen in "lepra reaction" in cases of nodular leprosy, which are often associated with a permanent increase in the leprous infection. It is considered inadvisable to describe both these conditions under the one term "lepra reaction" with no qualifying term to explain which type of reaction is meant.

6. The place of cases with tuberculoid macular lesions in the scheme of classification suggested by the Leonard Wood Memorial Conference is discussed. The opinion is expressed that in spite of the occurrence in them of changes which are leprotic in the sense of the Conference's definition, tuberculoid lesions are essentially part of the type of leprosy which has been described as " neural " or " maculoanæsthetic" leprosy, and should therefore be classified as such. The clinical, pathological and bacteriological findings made in these lesions are different from those made in lesions of nodular or " cutaneous " type, and the prognosis of cases with macular lesions is very much better than the prognosis of cases with cutaneous lesions. Therefore the differentiation of tuberculoid lesions from "cutaneous" lesions is a matter of considerable importance. 